\title{
EXISTE UM DIREITO FUNDAMENTAL À POSSE? ESTUDO SOBRE A RELATIVIZAÇÃO DO CONCEITO DE PROPRIEDADE IMOBILIÁRIA URBANA EM FACE DO DIREITO DE MORADIA
}

\section{IS THERE A FUNDAMENTAL RIGHT TO DWELLING? STUDY ON THE RELATIVIZATION OF THE CONCEPT OF URBAN REAL ESTATE PROPERTY TOWARDS THE RIGHT TO HOUSING}

\author{
Ana Carolina Batista ${ }^{1}$ \\ Josué Mastrodi
}

\section{Resumo}

O presente artigo versa sobre a relativização do conceito de propriedade imobiliária urbana e a possibilidade de se entender a posse como o real fundamento desse direito fundamental. Ao tratarmos sobre a colisão entre esses institutos, damos ênfase na posse de bens imóveis para residência urbana e sua identificação como direito de moradia que, embora declarado como direito humano e positivado como direito fundamental, ainda é tido como integralmente subordinado ao abstrato direito à propriedade. Para tanto, adotamos o método hipotéticodedutivo, visando a saber se o direito à propriedade pode ser compreendido a partir do direito à moradia, de modo a se subordinar a este. A pesquisa consistiu em revisão bibliográfica voltada às teorias possessórias e à teoria geral do direito sobre o desenvolvimento do conceito de propriedade, bem como das concepções de posse, da função social da propriedade, da função social da posse e do direito à moradia. Por meio desse procedimento metodológico, defendemos a inadequação operacional da propriedade abstrata, tal como desenvolvida pelas teorias possessórias do direito privado.

Palavras-chave: Posse como direito fundamental. Função social da propriedade. Função social da posse. Direito à moradia. Teoria geral do Direito.

\begin{abstract}
This article deals with the relativization of the concept of urban real estate property and the possibility of understanding possession as the real ground for the fundamental right of property. By dealing with the collision between these institutes, we focus on possession of real property to urban household and its identification as a right to housing that although declared as a human right and recognized as a fundamental right, it is still considered to be fully subordinated to the abstract right to property. For this purpose, we adopted a hypothetic-deductive method in order to confirm whether the right to property can be understood as the right to housing to be subordinated to it. The research consisted of a literature review oriented to possessory theories and the general theory of law on the development of the concept of property as well as the concepts of possession, the social function of property, the social function of possession and the right to housing. Through this methodological procedure, we advocate the operational inadequacy of abstract property, as developed by the possessory theories of private law.

Keywords: Possession as fundamental right. Social function of property. Social function of possession. Right to housing. General Theory of Law.

\footnotetext{
${ }^{1}$ Bacharel em Letras pela Universidade Estadual de Campinas (2012), Graduanda em Direito na Pontifícia Universidade Católica de Campinas. E-mail: carolbatista08@gmail.com

2 Doutor em Filosofia e Teoria Geral do Direito pela Universidade de São Paulo. Professor da Faculdade de Direito da Pontifícia Universidade Católica de Campinas. E-mail: mastrodi@puc-campinas.edu.br
} 


\section{INTRODUÇÃO}

Desde a Magna Carta inglesa de 1215 até os dias de hoje, os direitos humanos vêm sendo afirmados historicamente no sentido liberal de proteção, adequados à conformação dos interesses do grupo social dominante (burguesia) e à consolidação do capitalismo. Esse é o quadro histórico da proteção do direito à propriedade: o Direito dá preferência à proteção da propriedade abstrata, mesmo quando em conflito com uma posse concreta.

O presente artigo versa sobre a relativização do conceito de propriedade e a possibilidade de se entender a posse (ou o uso efetivo do bem) como o real fundamento desse direito fundamental, no âmbito da propriedade imobiliária urbana. Sob essa perspectiva, desenvolvemos a compreensão do instituto da posse a partir do direito de moradia e abordamos a colisão entre este direito (que é senão a aplicação finalística e concreta do uso de uma propriedade urbana) e o direito de propriedade.

Para tanto, ao adotarmos o método hipotético-dedutivo, partimos da hipótese, a ser confirmada, para saber se é possível não apenas relativizar a propriedade imobiliária urbana, mas subordiná-la ao direito à moradia, direito fundamental que, concretamente, identifica o uso efetivo do imóvel segundo sua função social. Realizamos uma revisão das teorias possessórias no item I, por meio da qual, primeiramente, introduzimos o objeto de estudo a partir das teorias de lhering e Savigny para, no item II, abordarmos o desenvolvimento do conceito de propriedade no pensamento jurídico ocidental no âmbito das teorias possessórias até a positivação da função social da propriedade na Constituição Federal de 1988, que é tratada no item III.

A partir disso, defendemos a inadequação operacional da propriedade abstrata, tal como desenvolvida pelas teorias possessórias do direito privado, nos casos envolvendo propriedade de imóvel urbano para fins de habitação, e buscamos investigar, no item IV, por meio de uma breve análise sobre as raízes da Teoria Geral do Direito, o porquê de a estrutura jurídica estar posta de modo a garantir a propriedade abstrata, independentemente da concreção de seu uso, embora a fundamentalidade desse direito, em termos reais e não jurídicos, esteja sustentada pelo exercício efetivo de sua posse.

À luz dessas considerações, apontamos, no item V, que a estrutura da Teoria Geral do Direito, no tocante às concepções de direito subjetivo e objetivo, somente se refere a um direito subjetivo de propriedade, mas não a um direito subjetivo de moradia, em razão de este direito fundamental social não ser compreendido sob os moldes do Direito Privado, isto é, estruturado em 
relações privadas, de crédito e débito, assim como ocorre com o direito subjetivo de propriedade, entre outros motivos, porque é confundido com o elemento posse do direito à propriedade e não como um direito social, fundamental e autônomo.

Por meio dessa abordagem, ao darmos ênfase na posse de bens imóveis para residência urbana e sua identificação como direito de moradia, passamos, no tópico $\mathrm{VI}$, a refletir especificamente sobre esse direito, o qual, embora declarado como direito humano e positivado como direito fundamental, ainda é tido como integralmente subordinado ao abstrato direito à propriedade. Para tanto, desenvolvemos uma reflexão que parte do conceito do direito à moradia, perpassa pela classificação de sua natureza jurídica interna e termina na questão de sua eficácia no contexto da realidade social brasileira.

Como essa realidade é muito mais complexa que a estrutura liberal criada para estipular que, no embate entre esses direitos, deve haver preferência ao direito à propriedade abstrata, entendemos possível seguir no sentido oposto e afirmar, em termos realistas, que é o direito fundamental à propriedade de imóvel urbano que decorre do direito fundamental à moradia.

\section{A INTRODUÇÃO DO OBJETO DE ESTUdO A PARTIR DAS TEORIAS DE SAVIGNY E IHERING}

Para o fim de questionar se existe um direito fundamental à posse, sob a perspectiva da relativização do conceito de propriedade em face do direito de posse, no âmbito da propriedade urbana, necessária se faz uma retrospectiva histórica que contenha, em primeiro plano, a influência de aspectos sociológicos, culturais e econômicos, não só quanto ao conteúdo normativo da noção de propriedade e posse, mas quanto ao conteúdo de suas próprias essências, estando qualquer definição conceitual, que ignore esses aspectos, destinada ao insucesso.

Nesse sentido, ao se debater sobre a atual estrutura teórica e normativa que confere licitude à propriedade, mesmo quando desvinculada do uso efetivo do bem (isto é, desvinculada da posse), é imprescindível um enfoque de caráter socioeconômico, que traga o desenvolvimento histórico do conceito de propriedade na sociedade ocidental.

Tendo-se em consideração, entretanto, que esse não é o fim do presente artigo, mas o meio para responder sua indagação de modo fundamentado e não lacônico, opta-se aqui, quanto ao tema, por um recorte histórico na evolução do pensamento jurídico ocidental, priorizando como ponto de partida, dentre os diversos autores que a esse objeto de estudo se dedicaram, Friedrich 
Carl von Savigny e Rudolf von Ihering se apresentam como destacáveis influências para o pensamento atual a respeito da teoria possessória, sendo ambos, em tal matéria, inevitáveis.

Por meio dessa abordagem, não se busca aqui esmiuçar e levar a juízo suas teses, mas tão somente, para o estudo da relativização do conceito de propriedade em face do direito de posse, resgatar a dimensão social que nelas se pode encontrar. Assim, de modo sucinto, é possível notar que, em matéria possessória, enquanto Savigny se ocupa, predominantemente, com o íntimo da atitude anímica, conformando-se com a vontade tendente para a propriedade (teoria subjetiva), Ihering identifica a subordinação desse instituto a uma realidade objetiva, defendendo a proteção possessória como exteriorização da propriedade (teoria objetiva).

Muitos foram os autores que, no sentido de avançar nesse debate, criticaram ambas as teorias como meio de introdução indispensável para uma abordagem da concepção de posse, sob o ponto de vista de sua significação social. Por exemplo, o antigo catedrático da Universidade de Madrid, Antonio Hernandez Gil (1969), em sua obra "La función social de la posesion":

Ihering, que dedicou um acúmulo de energias dialéticas para colocar a propriedade onde Savigny havia situado a pessoa- isto é, no centro da proteção possessória-, realizou um maior esforço para eliminar a posição que Savigny havia outorgado à propriedade: o animus domini (GIL, 1989, p.31, tradução nossa) ${ }^{3}$

Por meio desse recorte, relevante se faz a menção à obra "O fundamento dos interditos possessórios" - a partir da qual Ihering (1908, p.231) afirma a posse como exterioridade da propriedade, sendo aquela nada mais do que o estado normal externo da coisa, sob a qual se cumpre o destino econômico de servir aos homens. Sob essa perspectiva, a posse não seria mais do que um elemento acessório e dependente da propriedade, ignorando-se, portanto, a própria realidade, que é a posse, para se priorizar uma criação conceitual, qual seja, a propriedade.

Possível notar, por meio da leitura de tal obra, que, nela, a existência da posse há de explicar-se sempre como a condição de que depende o cumprimento de um fim racional da vida, e que, em cada caso concreto, esse instituto irá se referir à satisfação de uma necessidade.

Assim sendo, a tese lançada por Ihering, à compreensão do corpus na teoria subjetiva, não pode ser vista como insignificante no que tange à relevância prática, "pois fundamenta com primazia como um possuidor pode permanecer com tal status mesmo sem estar naquele momento

\footnotetext{
${ }^{3}$ Ou no original: Ihering, que dedicó un cúmulo de energías dialécticas a colocar la propriedad donde Savigny había situado a la persona- esto es, en el centro de la protección posesoria-, realizó um mayor esfuerzo si cabe para eliminar el emplaziamento que Savigny había otorgado a la propriedad: el animus domini. (GIL, 1989, p.31)
} 
dispondo de sua ingerência física sobre a res" (OLIVEIRA; MACIEL, 2009, p.8). Inegável, portanto, a colaboração desse filósofo do Direito do final do século XIX, em matéria possessória, no sentido de se afirmar que o corpus não se prende apenas à característica material, haja vista que, em sendo a posse das coisas a exterioridade da propriedade, aquela "acompanha sempre a utilidade econômica da propriedade e o proprietário não tem que recear que o direito o abandone, enquanto usar da coisa de um modo conforme seu destino" (IHERING,1908, p. 242).

Todavia, também não se pode olvidar que sua obra tratava a posse não de forma autônoma, mas tão somente como a aparência da propriedade, esta, sim, essencial, afirmando a proteção possessória como um complemento indispensável da propriedade. Assim, como afirmou o jurista espanhol Antonio Hernandez Gil (1969, p.32), na obra supracitada, "o realismo e a praticidade que, indubitavelmente, perseguem Ihering se traduziram em silenciar as motivações voluntaristas da posse, mas careceram de um alcance mais amplo"- motivo pelo qual, em sua opinião, quem se ocupe em debater a função social da posse, como prerrogativa corretora da propriedade, encontrará ponto de partida mais útil no formalista Savigny do que no realista Ihering, "já que aquele, ao colocar a posse ao serviço da pessoa e em missão de paz, se aproxima mais do mundo das realidades sociais do que Ihering" (GIL, 1969, p. 33).

Adota-se aqui, frente a tal visão, a necessidade de superação das teorias subjetiva e objetiva apresentadas, haja vista que, independentemente de qual possibilitaria um ponto de partida mais útil para a discussão em pauta, em ambas se encontra a inibição da tese da autonomia da posse, a qual é socialmente valiosa para o estudo da relativização do conceito de propriedade em face do direito de posse, sob o ponto de vista de que o gozo e a utilização dos bens adquirem significação jurídica fora da estrutura da propriedade, não sendo a tão só titularidade formal o suficiente para tanto. Não obstante, a superação de tais teorias se apresenta imprescindível para que se dê eficácia ao direito fundamental social à moradia, previsto no artigo 6으 da Constituição Federal de 1988. Direito à moradia que, de forma autônoma, se identifica com o direito à posse de imóvel para fim residencial.

\section{A EVOLUÇÃO DO PENSAMENTO JURÍDICO OCIDENTAL NO ÂMBITO DA TEORIA POSSESSÓRIA}

Inúmeros foram os autores que se dedicaram ao estudo da teoria possessória; uns de modo mais apurado, outros de modo mais superficial. Indubitável, entretanto, que, para fins de introdução ao tema do presente artigo, não será possível abordar todos aqueles que a essa matéria 
se dedicaram. Busca-se, desse modo, uma breve apresentação do que fora desenvolvido por aqueles que notável influência causaram neste estudo, no qual se busca compreender a posse como o elemento que confere a condição de direito fundamental ao direito de propriedade, de modo que a ausência daquela retiraria desta a sua fundamentalidade.

Para tanto, serão abordadas, individualmente, as obras dos autores Karl Renner e Antonio Hernandez Gil, assim como, sob as considerações e críticas constantes na obra desse, Silvio Perozzi e Raymond Saleilles - todos os quais colaboraram, nessa trajetória da evolução jurídica dos institutos aqui em pauta, ao terem concebido a propriedade privada não como uma condição prévia ou um antecedente lógico, mas como uma consequência da realidade social.

Nesse âmbito, embora não possua grande destaque frente aos outros autores supracitados, o jurista italiano Perozzi afirma, em sua obra "Istituzioni di Diritto Romano" (PEROZZI, 1928, apud GIL, 1969, p.49), que a posse não é uma relação de direito, sendo essa constituída por uma disposição de fato, para a qual em nada intervém a vontade estatal. Em sua percepção, a posse é tratada como uma relação ético-social, já que tem como base um costume, que forma parte da moralidade social - motivos pelos quais esse posicionamento se apresenta como um primeiro passo para a abordagem da posse como fenômeno social.

Críticas, no entanto, não faltaram quanto a essa visão, como bem simplifica GIL (1969), em sua análise sobre a teoria de Perozzi:

Perozzi engrandece somente como valor social da posse sua espontaneidade; é uma instituição consuetudinária, pré-estatal, baseada no próprio fato da abstenção surgida sem imposições. Trata-se de um primeiro passo, do qual não se obtém, entretanto, importantes consequências. Puro dado social sem sentido de sociabilidade e muito menos de socialização ${ }^{4}$ (GIL, 1969, p.53, tradução nossa)

Assim, embora seja válida sua tese no âmbito de uma explicação sociológica ou econômico-social, identifica esse autor na origem consuetudinária o aspecto social da posse, sendo ainda um avanço tímido, no âmbito da posse como fenômeno de relevância social, principalmente quando comparada àquela introduzida por Raymond Saleilles, notório jurista francês daquele mesmo século.

\footnotetext{
4 "Perozzi encarece solo como valor social de la posesión su esponteneidad; es una instituición consuetidinaria, preestatal, basada en el hecho mismo de la abstención surgida sin imposiciones. Trátase de um primer paso del que no se obtienen, sin embargo, importantes consecuencias. Puro dato social sin sentido de la sociedad y mucho menos de la socialización." (GIL, 1969, p. 53).
} 
Saleilles afirma em uma de suas principais obras ${ }^{5}$ que "a posse pode ser definida como a apropriação econômica das coisas, efetivamente consciente e querida" (SALEILLES, 1910-11, apud GIL, 1969, p. 16), ressaltando que esse instituto é constituído pelo simples fato de aparecer o detentor como dono da coisa, a partir do ponto de vista econômico. Sob tal perspectiva, assim como o fez Perozzi, Saleilles traz uma concepção de posse que, quando comparada àquelas clássicas desenvolvidas por Savigny e Ihering, implicam em um grande passo para a visão sociológica e econômico-social da posse, no sentido de repelir, de modo peremptório, ao menos que formalmente, a necessidade de apropriação jurídica ou propriedade para a existência da posse.

Desse modo, ele afirma que sua teoria traz a independência da posse em relação à propriedade, ratificando que aquela não se inventaria para servir de sustentáculo a esta, haja vista que o instituto da posse the é anterior; é a partir de então que seu conceito econômico vem substituir o jurídico: o que importa, nesse momento, é a apropriação econômica das coisas, sem relação alguma com a possível existência de um direito sobre a coisa.

Em tal linha de raciocínio, deve-se citar também Karl Renner, que considerou o interesse social como legitimador do direito de propriedade, preocupando-se, segundo ressaltado na introdução de sua obra "The Institutions of Private Law and their Social Functions", com a sociologia da lei e, mais particularmente, com o impacto das forças econômicas e mudanças sociais sobre as alterações no funcionamento dos institutos legais. Nesse sentido, afirma o sociólogo A. Javier Treviño, na introdução da obra de Renner:

Todos os processos econômicos são, por si mesmos, parte e parcela dos processos sociais de produção e reprodução da manutenção das espécies humanas. Institutos legais podem e devem ser compreendidos como ferramentas usadas pela sociedade para alcançar seu fundamental objetivo. Eles são peças de engrenagem no mecanismo de produção, consumo e distribuição do produto social. A isso é o que Renner dá o nome de função social. ${ }^{6}$ (RENNER, 1981, p.5, tradução nossa).

\footnotetext{
${ }^{5}$ Saleilles, Introducción a les méthodes juridiques ("Leçons faites au Collège des Sciences sociales", 1910-11, p. XVI).

6 "All economic processes, however, are themselves part and parcel of the social processes of 'production' and 'reproduction' of the maintenance of the human species. Legal institutions can and must be understood as the tools used by society in achieving this ultimate aim. They are cogs in the mechanism of the production, comsumption and distribution of the social product. This is what Renner calls their social function" (Renner, 1981; p.5).
} 
Dessa forma, revela esse jurista, em sua tese, a distinção entre função econômica e função social, sendo aquela "constituída por um processo único que pode se valer de uma pluralidade de institutos jurídicos, ao passo que a função social seria uma consequência da atuação do processo econômico no meio social" (PEIXOTO, 2005, p.24) - razão pela qual há aqui também uma notável contribuição no sentido de apontar a influência exercida pela sociedade para a compreensão desse fenômeno jurídico.

Nessa trajetória da posse vista como realidade dinâmica, tecida de interações do homem no mundo da convivência, inevitável se faz a menção a Antonio Hernandez Gil e sua já referida obra "La función social de la posesión", na qual ele procura considerar questionamentos como o porquê de haver tanta atração pela função social da propriedade e tão pouco pela da posse.

Nessa obra, resultado de grande reflexão sociológica, traz o antigo catedrático da Universidade de Madrid toda a evolução doutrinária em matéria de posse, partindo desde as concepções tradicionais de Savigny e Ihering, acompanhadas das críticas da explicação técnicojurídica da posse, até alcançar a discussão de sua concepção sociológica e econômica, na qual aborda Perozzi e Saleilles, com diversas considerações, dentre as quais as já acima expostas. Segundo Gil, um jurista:

Quando se situa diante da posse, deve adotar duas atitudes fundamentais: uma de tentar iniciar desde o princípio; intuir a primeira essência que emana do contato do intelecto com as coisas; buscar o que muitos outros têm buscado e que dificilmente se pode transmitir com tal busca (...). Ademais, precisa ter consciência do caráter peculiar da matéria. Deve-se despojar de juízos de valores e critérios, aptos para o tratamento de outras questões que aqui atuariam melhor como prejuízos perturbadores (GIL, 1969, p.13, tradução nossa). ${ }^{7}$

Defende esse autor que, em última instância, a posse se oferece como função-estrutura em qualquer regime econômico da sociedade: no capitalismo, com a liberdade individual exaltada e as necessidades coletivas reprimidas, tende a ser corretivo da propriedade monopolista de alguns, abrindo espaço ao processo socializador e, numa sociedade socialista, dada a posição recíproca inversa de liberdade e necessidade, manifesta-se também como corretivo da propriedade estatizada e atua como reduto da liberdade pessoal.

\footnotetext{
7 "Cuando se sitúa ante la posesión, tiene que adoptar dos actidudes fundamentales. Uma es la de intentar empezar desde el principio; intuir esa primera esencia que emana del contacto del intelcto con las cosas; buscar lo que tantos han buscado y que difícilmente se puede transmitir como tal busqueda (...). Además precisa tener consciência del carácter peculiar de la materia. Hay que despojarse de una serie de juicios y critérios,aptos para el tratamiento de otras cuestiones, que aquí actuarian más bien como prejuicios perturbadores." (GIL, 1969, p.13)
} 
Afinal, segundo sua reflexão sobre essa tese, é certo que, em uma ou em outra sociedade (lembrando que Gil escrevia numa época em que o mundo estava bipolarizado entre Estados capitalistas e Estados socialistas), mesmo que por diferentes vias, o direito de propriedade se retraiu e, onde isso ocorreu, houve o clamor necessário das necessidades da massa para o novo significado da posse.

A prática é entendida, nesse raciocínio, em seu mais completo alcance, ou seja, a vida social como problema em constante reconsideração para dar vida ao que o autor intitula de dialética da totalidade, que nada mais seria do que a ponderação do interesse coletivo encarnado pela sociedade; "totalidade aqui significando integração comunitária, presença da sociedade por meio do trabalho, como meio de afrontar as necessidades individuais e como realização da existência compartida" (GIL, 1969, p.149).

Vê-se, nesse estágio, direta relação com o que o presente artigo irá se preocupar adiante: a posse como o que verdadeiramente permite a relação entre proprietário e um bem, sendo esta que distinguirá um (o possuidor) de outro (o que não possui) e que determina a relação social entre as pessoas.

Por meio da apresentação de tal evolução jurídica sobre a matéria possessória, evidenciase, pois, a compreensão da posse como o elemento que confere a condição de direito fundamental ao direito de propriedade.

Por meio da adoção da explicação sociológica ou econômico-social, não é mais possível se prestar a pensar unicamente nas coisas em si mesmas, clama-se aqui por uma preocupação de ordem social.

\section{A POSITIVAÇÃO DA FUNÇÃO SOCIAL DA PROPRIEDADE}

A função das normas jurídicas é "a sua vocação, a sua finalidade, o 'para que' se destinam, o propósito a que servem. Evidentemente, cada uma delas pode apresentar múltiplas funções" (PENTEADO, 2012, p.198). Assim, dizer que existe função social da propriedade significa que, embora esse direito ainda seja concebido em seu interesse individual, no âmbito da propriedade privada, este também terá o dever de se ajustar, ou ao menos tencionar, para o atendimento de um interesse social.

Essa função social, em certo aspecto, sempre esteve presente nos diferentes momentos históricos, mas "apenas após a I Guerra Mundial foi que os vetores do ordenamento alcançaram 
outra direção para apontar a maximização do proveito para toda a coletividade, não se contentando mais com um genérico proveito coletivo indeterminado" (idem, p.202).

No direito, seu marco fundamental está na Constituição Mexicana de 1917 e na Constituição de Weimar de 1919, a partir das quais a estrutura de direito função se dá, segundo PENTEADO (2012, p.196), em termos de dever puro e simples, introduzindo uma obrigação na estrutura do direito subjetivo, com a famosa disposição "a propriedade obriga", constante no texto de Weimar.

Tal norma constitui, indubitavelmente, o primeiro passo na instrumentalização da função social, sobrepondo-se à visão de caráter individualista que, até então, predominava. Acompanha, nesse sentido, a evolução jurídica em matéria possessória aqui apresentada e, ainda que essa normatização não traga a posse como instituto autônomo, tamanho amadurecimento advém daí, como fruto de discussões filosóficas e sociológicas, como as anteriormente mencionadas, assim como pela influência de movimentos sociais do século XIX e do pensamento da Igreja Católica que, embora não tenham sido abordados na presente síntese dos estudos realizados para o início deste artigo, apresentam inegável relevância para a evolução dos institutos em análise.

Sob tal ótica, apesar de ser a propriedade ainda tida como meio de garantia da liberdade individual, sua nova roupagem busca servir como instrumento de realização de justiça social, marca de correção do liberalismo, pois que, no Estado Contemporâneo, após todas as lutas e conquistas sociais, "seria indesculpável anacronismo se a doutrina e a jurisprudência hodiernas não levassem em consideração essa transformação histórica, para adaptar o velho instituto às suas novas finalidades" (COMPARATO, 1997, p. 10).

No direito brasileiro, tal preocupação se instrumentaliza na Constituição de 1988, no inciso XXIII do artigo $5^{\circ}$, de que a propriedade atenderá sua função social. A partir dessa disposição, impõe-se um novo olhar direcionado ao direito civil:

Tem-se de regulamentação da atividade econômica individual, entre homens livre e iguais, para a regulamentação da vida social, na família, grupos comunitários(...), onde quer que a personalidade humana melhor se desenvolva e sua dignidade seja mais amplamente tutelada. (MORAES, 1991, p.9).

Configura-se, a partir de então, o necessário atendimento da disciplina estabelecida no Código Civil Brasileiro aos enunciados constitucionais que não mais tratam o instituto da propriedade em termos absolutos, mas dependentes da efetivação de valores que terão como finalidade, em último grau, a realização da justiça social em seu sentido material. 
Traduz-se, assim, a função social da propriedade, aparentemente, como um meio termo entre a propriedade absoluta dos liberais e os reclamos socialistas pela extinção da propriedade privada, por meio do mesmo raciocínio que aponta para o fato de que "a Teoria Geral do Direito, construída com base na preservação dos interesses próprios da burguesia revolucionária, gera reflexos na realidade social contemporânea" (MASTRODI, 2012, p.148).

A respeito dessa reflexão, Luciano de Camargo Penteado, em sua obra "Direito das Coisas", dedica um capítulo somente para a discussão da função social da propriedade e, ao analisá-la, postula que:

Trata-se a função social da propriedade, no sistema vigente, de uma cláusula geral, e, portanto, classifica-se entre as cláusulas gerais, que são regras, dotadas de tal grau de generalidade na sua redação que permitem, ora na fattispecie, ora na estatuição, e em certas circunstâncias em ambas, que permitem de modo mais claro a construção da norma do caso, porque, através delas não estão claramente definidos os casos que serão regulados e ou a forma em que se dará a regulação. A intenção normativa está ainda mais oculta no texto da cláusula geral. São autorização para produção de direito novo (normas secundárias), dentro do contexto valorativo. Talvez este o verdadeiro mérito das cláusulas gerais e o seu grande e temido poder (PENTEADO, 2012, p. 202).

Defende esse autor, por tal ótica, uma interpretação da função social da propriedade que ultrapassa a simples obrigação do proprietário, não a encarando apenas como dever legal que limite o uso, o gozo e a disposição do bem, mas como mecanismo positivo que haverá de atuar de maneira construtiva para o que intitula de gestão da propriedade mais fecunda, sendo tal normafunção vista, nesse âmbito, como modo de agir.

No entanto, mesmo com a positivação da função social, a proteção da propriedade permanece mais forte que a proteção da posse: o proprietário não precisa provar a legitimidade de sua propriedade, isso já é presumido pelo sistema jurídico; ao contrário do possuidor, que é obrigado a demonstrar que possui um bem de boa-fé e para finalidade adequada.

Em que pese a função social da propriedade ter sido positivada em 1919 na Alemanha e em 1917 no México, a eficácia dessa norma só se deu muito tempo depois. Até hoje, o individualismo no campo do direito tem priorizado a proteção da propriedade abstrata e de modo (quase) absoluto, sem muita consideração à força normativa de sua função social.

Transferindo essa problemática para o âmbito da teoria dos direitos fundamentais, constata-se que a posse não é estabelecida normativamente como um direito fundamental, não podendo ser posta em ponderação quando colidente com o direito de propriedade, já que ainda se tem aquela como acessória desta (MASTRODI, 2014, p.586 e 589). 
Nesse contexto, válido ressaltar que a posse possui proteção jurídica no Brasil, em especial nos artigos 1228, $\S 4^{\circ}$ e 1238 a 1244, todos do Código Civil. Trata-se da usucapião, que é a possibilidade de aquisição da propriedade por meio de uma posse ininterrupta de um bem sem oposição de seu proprietário. Não obstante, trata-se de uma modalidade de aquisição prescritiva, quase uma penalidade ao proprietário formal que não cuidou de seu bem. Também serve para esclarecer que essa é a exceção à regra que determina que a propriedade sempre prevalece em relação à posse. Não obstante, a posse para fins de habitação, nos termos desta pesquisa, será compreendida como sinônimo do direito fundamental à moradia.

Nesse sentido, trazendo todo o embasamento teórico aqui explorado para o confronto com a realidade que o presente artigo almeja, no âmbito da propriedade urbana para fins de moradia, faz-se possível compreender a problemática em pauta: a colisão entre o direito de moradia (que é senão a aplicação finalística e concreta do uso de uma propriedade urbana) e o direito de propriedade, com a consciência de que existe uma estrutura de dominação por detrás da realidade social que fundamenta todos os direitos fundamentais.

Será a posse concreta sempre subordinada à propriedade abstrata? Ou será que a fundamentalidade do direito de propriedade pode ser mais bem compreendida justamente a partir de seu componente concreto, a posse? Tais indagações ainda se resumem àquela que mais expressa o cerne da questão para a comprovação da hipótese aqui defendida: se a propriedade é direito fundamental quando permite o exercício da posse, por que a estrutura jurídica está posta de modo a garantir abstratamente a propriedade, independentemente da concreção de seu uso?

Para prosseguir na reflexão que busca responder essa última questão, delineando-se para a compreensão da posse como o elemento definidor da fundamentalidade do direito à propriedade, deve-se ter em mente que, ao se afirmar que a propriedade abstrata é aproveitada por todos os homens, no sentido de que todos têm o direito de buscar adquirir e possuir bens, assim como o faz a Teoria Geral do Direito, deixa-se de lado o fato fundamental que apenas alguns possuem bens, e que todos os demais (não possuidores) acabam se submetendo aos interesses dos possuidores.

\section{O DIREITO DE PROPRIEDADE SEGUNDO A TEORIA GERAL DO DIREITO}

Deve-se apontar, de início, que a Teoria Geral do Direito está distante de ser uma ciência com respostas prontas, ao contrário do que possam imaginar muitos daqueles que a buscam para a conceituação de diversos institutos, primordiais para o estudo do direito. 
Para sua abordagem, requer-se, ao menos, uma breve retrospectiva histórica que leve em consideração a influência de aspectos políticos, culturais e socioeconômicos que estiveram presentes em seu nascedouro, haja vista que, ao serem suas raízes investigadas, poder-se-á constatar que "na Europa, já entre o final do século XVIII e começo do século XIX, a teoria do direito servia de doutrina descritiva dos ideais iluministas da burguesia revolucionária" (MASTRODI e SILVA, 2012, p.3), sendo sua base, pois, eminentemente de caráter liberal.

Há, justamente no âmbito das revoluções burguesas, com destaque para a Revolução Francesa, em 1789, a positivação jurídica de determinados direitos que a classe social predominante, a burguesia, defendia de modo idealizado como direitos naturais pertencentes a todos os homens. Esses ideais de liberdade, de igualdade e de fraternidade- posteriormente tidos como direitos fundamentais, respectivamente, de primeira, de segunda e de terceira dimensões ${ }^{8}-$ não passavam, na verdade, de aspirações a partir das quais uma nova ordem seria estabelecida e jamais seriam, naquela estrutura econômico-social, passíveis de concretização por todos os membros da sociedade, assim como continuam, hoje, sem concreção.

Naquele momento, tendo sido a propriedade privada "reconhecida como garantia última da liberdade individual, tornava-se inevitável sustentar que a ordem jurídica deveria proteger não apenas os atuais, mas também os futuros e potenciais proprietários" (COMPARATO, 1997, p.3), tendo sido o direito de propriedade, assim, elevado a direito do homem e, por conseguinte, identificado como algo sagrado pelo artigo 17 da laica Declaração dos Direitos do Homem e do Cidadão de $1789 .^{9}$

Não se pode olvidar que esse direito, em realidade, sempre foi entendido como direito fundamental, antes mesmo da existência da teoria dos direitos fundamentais e da positivação constitucional dos direitos humanos como direitos fundamentais. ${ }^{10}$ Opta-se aqui, entretanto, por

\footnotetext{
${ }^{8}$ Em relação aos direitos de segunda e de terceira dimensões, deve-se apontar que, enquanto aqueles foram impulsionados a partir do século XIX, com destaque para a Revolução Industrial, e se relacionaram pela luta por melhores condições de trabalho, direitos sociais, econômicos e culturais; os de terceira dimensão tratam dos direitos chamados transindividuais, preocupados com a coletividade humana, com destaque para direitos de solidariedade e fraternidade, além da preservação ao meio ambiente.

9 "Art. XVII. A propriedade é um direito inviolável e sagrado..." (g.n.: "La propriété étant um droit inviolable et sacré, nul ne peute nêtre privé, si ce n'est lors que la nécessité publique, légalement constatée, l'exige évidemment, et sous la condition d'une juste et préalable indemnité.") Cf. http://www.assembleenationale.fr/histoire/dudh/1789.asp.Acesso em 7 de março de 2013.

${ }^{10}$ Tanto os Códigos Civis francês de 1804 e os brasileiros de 1916 e 2002 são organizados essencialmente sobre os conceitos idealistas de sujeito de direitos e de propriedade (privada), para estabelecimento das condições para qualquer um ser proprietário e para proteger ou alienar sua propriedade.
} 
um recorte histórico a partir da Revolução Francesa, momento no qual foram amplamente defendidos direitos relacionados à proteção do indivíduo frente ao Estado.

Nesse período, em que se reconhece o início do Estado moderno, há o estabelecimento de condições políticas e jurídicas para proteção da propriedade - o que interessava predominantemente aos burgueses, e não ao terceiro estamento em geral. Tendo a Teoria Geral do Direito sua origem nessa fase histórica, de luta política pela emancipação da burguesia do estamento nobiliárquico e de transição político-econômica para o liberalismo, não é de se surpreender que a compreensão da estrutura jurídica do Estado e das relações entre particulares tenha se desenvolvido com base em princípios cujas moralidade e racionalidade derivaram de circunstâncias de uma ordem econômica liberal.

Por meio de tal ótica, compreende-se o conceito de propriedade de forma abstrata, não havendo distinção entre a propriedade de um bem de consumo, a propriedade de um bem de produção ou de um imóvel para moradia: a finalidade do bem ou a necessidade de seu uso não foram considerados.

De tal modo, a Teoria Geral do Direito, diante dos interesses econômicos predominantes à época, "teria como interesse exclusivo descrever e analisar o direito em si, graças ao emprego de um método científico, e aspiraria ser isenta de qualquer julgamento de valor" (TROPER, 2008, p.92), abordando, nesse sentido, a propriedade como aquela que protegeria, abstrata e indistintamente, a moradia, o bem de consumo e o bem de produção.

Desse modo, indubitável que os interesses políticos e socioeconômicos predominantes à época direcionaram, assim como ainda direcionam (apesar das atuais limitações ao direito de propriedade $)^{11}$ a proteção deste instituto em detrimento do instituto da posse, já que a estrutura original da referida Teoria, baseada em direitos individuais absolutos e de não intervenção estatal, sequer levava em conta que aqueles direitos de segunda ou de terceira dimensões pudessem existir, em razão da incompatibilidade com o sentido de sua própria base individualista, que, ao estruturar o direito na forma de garantias absolutas entre sujeitos de direito de igual dignidade perante a lei, permanecia cega às necessidades da realidade social.

Cristaliza-se, então, a ideia da propriedade como aquela que engloba o conceito de posse instituto este entendido, grosso modo, como mero fenômeno decorrente da essência da

\footnotetext{
${ }^{11}$ São limitações legais ao direito de propriedade a função social, a vedação aos atos emulativos, a sujeição à desapropriação, tanto pública quanto privada, o dever de respeito à saúde, sossego e segurança dos vizinhos, a responsabilidade ambiental, as limitações administrativas e urbanísticas (PENTEADO, 2012, p.188).
} 
propriedade, visão condizente com a teoria objetiva defendida por Ihering (cf. tratado no item I), combatida no plano constitucional pela relativização do direito à propriedade, por sua função social, e também por meio da hipótese do presente artigo, qual seja, de subordinação da propriedade do imóvel residencial urbano à moradia: o direito à moradia, nesse sentido, deve ser compreendido como superior ao direito à propriedade.

\section{DO DIREITO DE PROPRIEDADE AO DIREITO DE MORADIA, UMA ANÁLISE À LUZ DA CONCEPÇÃO DE DIREITO SUBJETIVO}

Ainda no âmbito deste estudo, dentre os conceitos jurídicos variados que fazem parte do escopo da Teoria Geral do Direito, importa contrapor os chamados direito objetivo e subjetivo aos direitos fundamentais, já que esses conceitos acabam por refletir, materialmente, as raízes da visão de mundo que os define.

Essa Teoria, como já mencionado, se relaciona, no âmbito jurídico, com a elaboração de conceitos gerais e permanentes, por uma perfeição sistêmica das normas de direito, muitas vezes sem correspondência com a realidade, já que as relações sociais travadas entre pessoas, à luz ou não do direito positivo, não são, de modo algum, homogêneas, embora sejam, por aquela Teoria, assim tratadas.

Ademais, sua base eminentemente liberal traz consequências que não se restringem ao plano teórico da discussão aqui em pauta, mas atingem também e, principalmente, o plano da realidade social contemporânea, "ainda mais quando se põe a relacionar o que esta teoria define como direito objetivo ou subjetivo" (MASTRODI e SILVA, 2012, p.148).

A fim de melhor compreender essa afirmação, deve-se, inicialmente, tratar da distinção entre esses conceitos, usualmente definidos de modo generalizado: o direito objetivo como a norma posta, reflexo do próprio ordenamento jurídico sistematizado, e o direito subjetivo, por sua vez, como a possibilidade de exercício do sujeito, em conformidade com aquelas normas positivadas.

Sobre essa diferenciação, um dos mais notórios juristas do século XX, Hans Kelsen, em sua obra Teoria Pura do Direito (2000, p. 149), afirma:

Ao direito subjetivo de alguém, que apenas é o reflexo do dever jurídico de outrem, se refere a definição, muitas vezes encontrada na jurisprudência tradicional, segundo a qual o direito subjetivo é determinado como interesse juridicamente protegido(...). Do ponto de vista de uma concepção que encare o Direito como norma ou sistema de normas, porém, o direito 
subjetivo não pode ser um interesse - protegido pelo Direito-, mas apenas a proteção ou tutela deste interesse, por parte do Direito objetivo.

Tal concepção se faz, no âmbito da presente discussão, um tanto quanto lacônica e deve ser deixada de lado para o desenvolvimento de um aprofundamento mais crítico, que ajude não somente a ampliar o debate existente e até aqui desenvolvido entre posse e propriedade, mas, muito além disso, abrir espaço para um olhar que atinja a realidade social atual envolvida no âmbito da propriedade urbana, qual seja, aquela sobre a qual se vê a possibilidade de identificação da posse de imóvel urbano, segundo a função social, com o direito à moradia -implicando tal vínculo, diretamente, na relativização do conceito de propriedade e na sua subordinação ao direito de moradia.

Há autores que buscam, na abordagem do direito subjetivo de propriedade, apontar soluções de ordem antropológica e filosófica frente àquela dicotomia conceitual; assim o faz Federico Bonaldo (2013), em seu artigo "O Direito Subjetivo de Propriedade em Face da Coexistência humana". Neste, aponta o autor que, tal como positivado no Código Civil vigente, a noção técnica de direito subjetivo de propriedade traz o uso, o gozo e a disposição como os três principais atributos da propriedade, assim como o direito de perseguir a coisa, quando perturbado o domínio de alguém. Por mais que existam aí as limitações abordadas (vide tópico anterior), vê-se que a doutrina moderna ainda considera a propriedade sob sua face plena e exclusiva.

Consciente de que essa abordagem está muito distante de acolher a estrutura social vigente, diante da existência de tamanha desigualdade social e injustiça, desenvolve o referido autor um conceito de direito subjetivo de propriedade sob uma perspectiva antropológica dual, "isto é, que concebe o indivíduo humano, a um só tempo, como uma existência irredutivelmente individual e necessariamente coordenada com os demais seres humanos" (BONALDO, 2013, p.2) interpretação por meio da qual se busca o elemento-chave para a definição da propriedade: a necessária associação entre as pessoas para o atendimento de suas necessidades essenciais, identificando tal instituto no vínculo entre um homem e outro, mediada pela coisa.

Nesse contexto, da necessária associação entre as pessoas para o atendimento de suas necessidades essenciais, na qual estão presentes condutas com influências recíprocas, há a existência não só de relações sociais, mas de relações de direitos, quando são estas submetidas à disciplina das normas jurídicas.

Tem-se aqui o conceito de obrigação, o qual nada mais séria do que um dever jurídico exigível de pessoa ou grupo individualizado, por meio do qual se constata, de um lado, a posição passiva de quem possui uma pretensão (poder jurídico daquele que é titular de um direito 
subjetivo) e, de outro, a posição ativa daquele a quem será exigida a realização de determinado comportamento.

Nota-se, diante da descrição de tal relação, que direito e obrigação são aqui correlatos, cabendo a um dos polos da relação jurídica o direito subjetivo (crédito) e a pretensão e, ao outro, restam o dever jurídico (débito) e a obrigação.

É sobre essa base de princípios liberais, pertencente ao Direito Privado e ao trato das relações entre particulares, que se constrói a concepção de direito subjetivo, ou seja: deve haver, para o exercício desse direito, a existência de uma relação de caráter patrimonial em que cada um ocupa uma posição - de crédito ou de débito, de direito ou de dever.

Ao contrário disso, a ideia de direito subjetivo que aqui se quer desenvolver é aquela que se compactua com a adotada em sua perspectiva realista, "segundo a qual existe um Direito não apenas quando uma norma em vigor (válida juridicamente) o garante, mas sim quando a conduta fática na realidade social o exprime" (MASTRODI e SILVA, 2012, p.156). Assim, é justamente na ideia de que a propriedade é, em verdade, relação entre homem e homem, mediada pela coisa e de que, nesse âmbito, está adstrita a exercer uma função de ordem social, que se chega, no âmbito da propriedade urbana, ao possível embate entre o direito de moradia (que não é senão a aplicação finalística e concreta do uso de uma propriedade urbana) e o direito de propriedade.

Entretanto, quanto ao direito de moradia, não se pode olvidar que o Estado Liberal foi criado para garantir e proteger, essencialmente, as relações jurídicas privadas e que os direitos subjetivos também foram edificados justamente sobre esse terreno, cuja principal característica é a relação de créditos e débitos (MASTRODI, 2014, p. 580). Diante desse cenário, os direitos sociais, como o direito fundamental social de moradia, não funcionam como direitos subjetivos, haja vista que não há quem na sociedade tenha o dever de cumprir esse crédito em favor de alguém.

De forma contraditória, então, busca-se aplicar uma lógica tipicamente do Direito Privado para o trato de relações jurídicas que envolvam direitos sociais que, diversamente daqueles, não possuem sujeitos, desde logo, individualizáveis, tampouco delimitação exata da repercussão patrimonial envolvida. Não é difícil perceber, diante do conteúdo dessas relações, que sua estrutura fechada e aparentemente perfeita é insuficiente para a materialização dos direitos sociais, justamente por se moldar em critérios objetivos e condições bem definidas, o que não é cabível em matéria de direitos fundamentais e sociais.

Embora esteja expresso o dever do Estado, na Constituição Federal de 1988, de garantir direitos sociais (como a educação, o trabalho, a moradia, o lazer, a segurança e a assistência aos 
desamparados), tal missão possui, na realidade, cunho essencialmente programático, inexistindo, até mesmo, ação judicial que faça obrigatória sua prestação a cada um que deles necessite.

A promoção desses direitos, presentes no artigo 6o da Constituição da República, é, na prática, promovido por meio de políticas públicas, somente a partir da disponibilidade orçamentária estipulada pelo administrador público (matéria está reservada, especialmente, ao Direito Orçamentário) - o que nada mais faz do que reforçar a lógica privada supramencionada, na qual se constata a compreensão de todos os direitos sob a perspectiva de dois polos: o ativo, do crédito, e o passivo, do débito.

Logo, em oposição aos direitos de primeira dimensão (dentre os quais se destaca o direito de propriedade), "que são reconhecidos como direitos subjetivos claramente exigíveis pela Teoria Geral do Direito, o direito fundamental social à moradia necessita da promulgação de leis e regulamentos específicos para que ele se realize" (MASTRODI e SILVA, 2012, p.14).

Há, diante do exposto, causas históricas que levaram a essa conformação social de imediata exigibilidade dos direitos de liberdade, em contraposição à subordinação dos direitos sociais à intervenção estatal.

Sobre esse tópico, cujo fim é esclarecer, no âmbito do direito subjetivo e sua respectiva exigibilidade, a distinção dos direitos de primeira e de segunda dimensões, Norberto Bobbio, um dos grandes filósofos do século XX, em sua obra "A Era dos Direitos", afirmou que os direitos de liberdade negativa, dentre os quais se inclui o direito de propriedade, são os primeiros direitos a serem reconhecidos e tutelados, porém, afirma que esses têm valia somente para o homem abstrato, razão pela qual, já em seu nascedouro, foram denominados direitos do Homem.

Subentende-se, quanto a esses direitos, a falsa existência de uma relação de igualdade entre todos os membros da sociedade- pensamento este que, como já anteriormente mencionado, se relaciona com a estrutura original da Teoria Geral do Direito, a qual é apática às necessidades da realidade social.

Tal "universalidade (ou indistinção ou não discriminação) na atribuição e no eventual gozo dos direitos de liberdade não vale para os direitos sociais, e nem mesmo para os direitos políticos, diante dos quais os indivíduos são iguais só genericamente, mas não especificamente" (BOBBIO, 2004, p.65). A crítica aqui, relacionada ao não cabimento de um trato universal no âmbito dos direitos sociais, é desenvolvida pelo autor com o fim de apontar que, estando em jogo questões relacionadas a esses direitos e aqueles de primeira dimensão, imprescindível se faz o reconhecimento de que o critério da diferença pode ser de grande relevância no primeiro caso, em 
que as individualidades entre um ser humano e outro compõem o cerne, o porquê daqueles direitos.

Nesse sentido, em face da distinção entre as duas mencionadas categorias de direitos, deve-se apontar, assim como o fez o referido filósofo, que, no campo da realização prática, a tutela dos direitos sociais, diversamente dos direitos de liberdade (aqueles de primeira dimensão), necessitam de uma sólida intervenção do Estado, pelas mais diversas políticas públicas, já que aqueles não detêm a proteção consolidada que esses possuem. Ou seja, é justamente pela ampliação dos poderes do Estado que se deve buscar a tutela efetiva desses direitos, dentre os quais, o direito à moradia.

Assim, em relação à usual concepção de direito subjetivo, a estrutura da Teoria Geral do Direito somente se refere a um direito subjetivo de propriedade, mas não a um direito subjetivo de moradia, haja vista que, conforme explorado, este não é passível de ser compreendido sob os moldes do Direito Privado, isto é, estruturado em relações privadas, dotado de uma matriz liberal assim como almejado nos conceitos primordialmente desenvolvidos pela Teoria Geral do Direito. Não obstante, parece-nos que a realidade social é muito mais complexa que a estrutura liberal criada para sua compreensão.

\section{DO DIREITO À MORADIA: CONCEITO, NATUREZA JURÍDICA E EFICÁCIA}

Ao serem questionados sobre o significado de moradia, muitos dirão, assim como define genericamente a grande maioria dos dicionários, que se trata de "lugar onde se mora ou permanece",;2 em outras palavras, o simples local onde a pessoa possa se estabelecer de forma não eventual.

Não é a partir dessa abordagem que a moradia é tratada nos mais diversos documentos oficiais e nos tratados internacionais que dela se ocupam; nestes, o que está em questão "não é apenas a moradia enquanto um objeto físico de quatro paredes, um teto, mas a moradia como possibilidade de acesso aos meios de vida, à água, a toda infraestrutura, à educação, à saúde" (ROLNIK, 2011, p.37).

No que diz respeito a esses documentos, vale frisar que o primeiro deles- cujo reflexo teve impacto internacional e determinante para o surgimento dos posteriores- foi a Declaração Universal dos Direitos Humanos, em 1948, no contexto do pós-segunda guerra mundial. Em seu

12 "Morada", in Dicionário Priberam da Língua Portuguesa, 2008-2013, http://www.priberam.pt/DLPO/morada. Acesso em 23-03-2015. 
conteúdo, apontou-se a habitação como direito do Homem, justamente interligado, conforme interpretação acima, com outros direitos que buscam garantir um padrão de vida digno à coletividade, conforme artigo XXV, I:

I. Todo homem tem direito a um padrão de vida capaz de assegurar a si e a sua família saúde e bem-estar, inclusive alimentação, vestuário, habitação, cuidados médicos e os serviços sociais indispensáveis, e direito à segurança em caso de desemprego, doença, invalidez, viuvez, velhice ou outros casos de perda de meios de subsistência em circunstâncias fora de seu controle. ${ }^{13}$

Apesar de incorporar essa preocupação com um padrão de vida digno ao homem, diante das atrocidades e mazelas sociais decorrentes daquele momento histórico, essa Declaração sempre foi interpretada de modo mais vinculado aos direitos de primeira dimensão, imersa ainda na busca de uma igualdade apenas formal, já que não possuía "distinção de qualquer espécie, seja de raça, cor, sexo, idioma, religião, opinião política ou de outra natureza, origem nacional ou social, riqueza, nascimento, ou qualquer outra condição", 14 segundo seu artigo 2o, inciso I.

Dezoito anos depois, o direito à moradia adquire mais visibilidade com o Pacto Internacional dos Direitos Econômicos, Sociais e Culturais (PIDESC), acolhido pela ONU em 1966 e ratificado, pelo Estado Brasileiro, após vinte seis anos. Conforme artigo 11, parágrafo 1으, daquele pacto,

Os estados- partes no presente Pacto reconhecem o direito de toda pessoa a um nível de vida adequado para si próprio e para sua família, inclusive à alimentação, vestimenta e moradia adequadas, assim como uma melhoria contínua de suas condições de vida. Os Estados- partes tomarão medidas apropriadas para assegurar a consecução desse direito, reconhecendo, nesse sentido, a importância essencial da cooperação internacional fundada no livre consentimento. ${ }^{15}$

Diante de tais disposições, abriu-se espaço para uma discussão cada vez mais ampla e recorrente sobre a questão do Direito à Moradia, dentre elas, a Primeira Conferência das Nações Unidas sobre Assentamentos Humanos, na cidade de Vancouver (Habitat-I), em 1976 e, em prosseguimento a esta, a Segunda Conferência das Nações Unidas sobre Assentamentos Humanos (Habitat-II), em 1996, em Istambul. ${ }^{16}$

\footnotetext{
${ }^{13}$ Disponível em: http://www.dhnet.org.br/direitos/deconu/textos/integra.htm. Acesso em: 24-03-2015

${ }^{14}$ DECLARAÇÃO UNIVERSAL DOS DIREITOS HUMANOS. Adotada e proclamada pela resolução 217 A (III) da Assembleia Geral das Nações Unidas em 10 de dezembro de 1948. Disponível em: http://unesdoc.unesco.org/images/0013/001394/139423por.pdf. Acesso em: 25.03.2015.

15 Disponível em: http://www.pge.sp.gov.br/centrodeestudos/bibliotecavirtual/instrumentos/direitos.htm. Acesso em: 24-03-2015

${ }^{16}$ Em relação ao andamento dessas Conferências, destaca-se que a Habitat III está prevista para ocorrer em Quito, Equador, em outubro de 2016, com o fim de revigorar as agendas anteriores, como meio de
} 
Interessante observar que, enquanto a primeira revela, dentre outros pontos, a necessidade de mais cooperação de alcance regional, nacional e internacional (no que diz respeito à promoção de políticas públicas que zelem pelo direito à moradia), a última aponta diretamente para "a adoção de medidas, governamentais e não governamentais, direcionadas ao enfrentamento de questões concernentes aos assentamentos humanos" (HEIS, 2013, p.19), nas quais se inclui, até mesmo, a frágil questão da regularização de assentamentos informais e favelas urbanas.

Juntas, as referidas Conferências representam um importante passo para a construção não apenas de ideais, mas de metas concretas, como um plano de ação global, no qual ambas as agendas, a Habitat I e a Habitat II, indicam diretrizes cujo maior fim se relaciona com o desenvolvimento de assentamentos humanos. Essas características, vale lembrar, compactuam exatamente com a noção de que o alcance à moradia implica em outros direitos humanos, por serem uns dependentes dos outros, no âmbito de um significativo processo de desenvolvimento social.

Deve-se ressaltar ainda, nesse contexto, que os documentos formais supramencionados estão longe de serem os únicos a comporem fundamentos normativos para o Direito à moradia. ${ }^{17}$ Dentre outros, devem-se destacar o Pacto Internacional de Direitos Civis e Políticos (1992); a Convenção Internacional sobre a Eliminação de Todas as Formas de Discriminação Racial (1968); a Convenção Sobre a Eliminação de Todas as Formas de Discriminação Contra a Mulher (1979); a Convenção sobre os Direitos das Crianças(1990); a Convenção sobre o status dos refugiados(1951); a Convenção 169 da OIT(2004); Convenção de Genebra (quarta) sobre proteção de civis em tempo de Guerra (1949); a Convenção Internacional para a Proteção dos Direitos de todos os Trabalhadores Migrantes e Membros de suas Famílias (1990) e a Declaração do Direito dos Indígenas (2008).

No que diz respeito ao texto da Constituição Brasileira, o direito à moradia foi incluído em seu artigo 6으, por meio da Emenda Constitucional no 26, de 2000, passando a ser expressamente nominado dentre outros direitos sociais. Deve-se apontar, porém, que -embora tenha havido somente naquele momento a citação desse direito, de modo independente- diversos são os

compromisso global para uma urbanização sustentável. Disponível em: http://unhabitat.org/habitat-iii/. Acesso em: 24-03-2015.

17 Projeto da Relatoria Especial do Conselho de Direitos Humanos da ONU para o Direito à Moradia Adequada. Disponível em: http://direitoamoradia.org/?page_id=975\&lang=pt. Acesso em 24.02.2015 
dispositivos, anteriores à mencionada Emenda, que já faziam referência expressa ao Direito à Moradia.

Nesse sentido, dentre outros dispositivos, cita o autor Ingo Wolfgang Sarlet (2003, p.341) tanto a vinculação social da propriedade (Constituição Federal, art. 5ํ, XXIII, e artigos 170, inciso III e 182, §2) quanto a previsão constitucional da usucapião especial urbana (art. 183) e rural (art. 191), os quais possibilitavam, mediante determinados requisitos, a constituição de domínio por meio do uso do imóvel para moradia.

Pontua o autor que o Direito à Moradia, acima de qualquer outra referência anterior, já poderia ser reconhecido como direito derivado do princípio da dignidade humana, este presente no art. 1으, inciso III, da Constituição Federal - haja vista não ser possível conceber uma vida digna ao ser humano, sem que the seja possível ter um lugar no qual possa se estabelecer e satisfazer suas necessidades não apenas vitais, mas todas aquelas que the proporcionem uma vida minimamente digna.

Não obstante, o reconhecimento do Direito à Moradia como direito fundamental, antes da Emenda Constitucional no 26 de 2000, baseado em uma pretensa dignidade da pessoa humana, nos parece extremamente idealista e abstrato. Afinal, nesse sentido, a moradia ficaria fundada num princípio genérico e abstrato, sem muita vinculação com a realidade prática. Mais razoável seria compreender que a moradia é uma necessidade real e concreta a ser satisfeita, um interesse social legítimo que deve ser constitucionalmente protegido.

Todos os direitos e as garantias constantes na Constituição (dentre elas, o direito à moradia) "não excluem outros decorrentes do regime e dos princípios por ela adotados, ou dos tratados internacionais em que a República Federativa do Brasil faça parte" (Constituição Federal, art. 5으, §2으, porém, no tocante à eficácia desses direitos, vale dizer que não é o texto constitucional que pauta a realidade social, mas a realidade social, segundo interesses predominantes na sociedade em cada tempo e lugar, que acabam por pautar a eficácia de um ou outro ponto do texto constitucional.

Nessa perspectiva, parece possuir relevância somente jurídica a constatação de que o direito à moradia "já era até mesmo expressamente consagrado na nossa ordem interna, pelo menos na condição de materialmente fundamental" (SARLET, 2003, p.342), por ser o Brasil signatário dos tratados internacionais que reconheciam esse direito, dentre outros, do supracitado PIDESC de 1966. Isso porque esse direito não passou a ter eficácia assim que foi validado como direito humano ou fundamental. Sem dúvida, ele é reconhecido com um direito constitucional 
válido, porém sua eficácia social se dá nos estreitos limites de políticas públicas de moradia que venham a ser implementadas, como se tais políticas, insuficientes para dar conta do déficit habitacional, fossem criadas apenas para dar alguma efetividade ao texto constitucional.

Essa mesma crítica deve se estender à referência ao conteúdo do termo "moradia" no texto constitucional, haja vista que de nada adianta afirmar que sua leitura exige a interpretação implícita do sentido de moradia adequada (aquela que representa muito mais do que "quatro paredes", conforme definição dada pela Recomendação n. 4 do Comitê das Nações Unidas para os Direitos Sociais, Econômicos e Culturais, de 1991), quando o que se vê, na realidade brasileira, são políticas públicas que, quando direcionadas para redução do déficit habitacional, trazem apenas resultados quantitativos e não qualitativos. Bem distantes, portanto, da leitura exigida pelos diversos tratados e documentos internacionais sobre moradia adequada.

A partir de um plano abstrato, muitos desses autores que defendem a fundamentalidade do direito à moradia em sua positivação, formal e material, desenvolvem a reflexão sobre a possibilidade de autoaplicação desses direitos, em face do questionamento sobre o alcance da abrangência conceitual e material dos direitos e garantias fundamentais, previstos no Título II da Constituição Federal de 1988. Sobre essa reflexão, necessário se faz também uma abordagem realista em contraposição àquela que se limita à letra da lei.

Trata-se aqui de uma breve análise do disposto no §2ํㅡ, do artigo 5o da Carta Magna. Evidente, por meio da leitura desse dispositivo, que seu conteúdo é materialmente aberto, "em virtude de existirem tantos outros direitos fundamentais que, por ocasião da impossibilidade da norma acompanhar a evolução dos tempos, poderão tornar-se assim capitulados em razão das necessidades humanas" (PAGANI, 2009, p.125).

Por meio do posicionamento que adota a possibilidade jurídica de abordar o direito à moradia como direito e garantia fundamental, ou seja, à luz do artigo 5ㅇ, $\S 2$, surge aqui uma questão de inestimável importância: seria possível, quanto a esse direito, discutir sua aplicabilidade imediata, conforme preconiza o artigo 5으, $\$ 1$ 으 da Constituição Federal de 1988, no tocante aos direitos e garantias fundamentais do Título $\| ?^{18}$

Não há dificuldades de se deduzir que, ao menos conceitualmente, seria possível estender a questão da aplicabilidade imediata a direitos que não estejam presentes no rol do artigo 5o, não

\footnotetext{
${ }^{18}$ Art. 5o Todos são iguais perante a lei, sem distinção de qualquer natureza, garantindo-se aos brasileiros e aos estrangeiros residentes no País a inviolabilidade do direito à vida, à liberdade, à igualdade, à segurança e à propriedade, nos termos seguintes:

(,,,) § 1 o As normas definidoras dos direitos e garantias fundamentais têm aplicação imediata.
} 
havendo qualquer impedimento para tanto, haja vista a abertura conceitual trazida pelo $\S 20$ desse mesmo artigo da Carta Magna.

Nessa perspectiva ideal, não poderia haver norma constitucional desprovida de direta aplicabilidade, haja vista que, até as que possuem teor eminentemente programático implicariam, por muitas vezes, na imposição de inconstitucionalidade de normas que a contrariassem ou, então, serviriam, ao menos, como parâmetro hermenêutico constitucional.

Vale dizer, entretanto, que a eficácia normativa não é fruto da organização jurídiconormativa, mas de uma realidade social e, nesse sentido, os autores que tratam desse tema, quanto à possibilidade de aplicação imediata de direitos sociais, parecem olvidar a estrutura socioeconômica sobre a qual essa discussão se assenta, qual seja, aquela que ainda resguarda os princípios do liberalismo econômico. Nesse sentido, afirmar a aplicabilidade imediata desses direitos somente em virtude do conteúdo formal que eles carregam parece inócuo diante do contexto social que permeia a dificuldade de sua efetivação.

Como já anteriormente explorado, ${ }^{19}$ diferentemente dos direitos sociais, os direitos individuais são aqueles que sempre receberam mais atenção, "justamente porque eles representam, no campo do direito, a estrutura econômica de dominação liberal inerente às sociedades ocidentais, e porque dão racionalidade a essa estrutura, permitindo o franco funcionamento do sistema capitalista" (MASTRODI, 2014, p. 583).

Não é de se estranhar, diante disso, que, no campo das normas de direitos e garantias fundamentais, as normas classificadas como de eficácia plena (que já possuiriam todo o necessário, desde sua promulgação, para uma eficácia plena) sejam mais de caráter liberal, relacionadas a direitos individuais, enquanto as de eficácia limitada (que, a fim de deterem eficácia, necessitariam de regulamentação por lei) sejam justamente as de caráter social, as quais, quando detêm alguma eficácia, é esta jurídico-programática. Torna-se claro, então que:

Ao mesmo tempo em que não sobram muitos recursos públicos para serem aplicados na garantia dos direitos sociais, isso retroalimenta o círculo vicioso da percepção pela qual direitos sociais não são tão importantes assim, ou que sua eficácia se encontra subordinada à proteção prévia dos direitos individuais. (MASTRODI, 2014, p.583)

Quanto a essa distinção entre normas de eficácia plena e de eficácia contida, largamente utilizada pelas doutrinas constitucionalistas em geral, relevante se faz uma pausa para apontar a crítica feita pelo autor Virgílio Afonso da Silva, em sua obra "O conteúdo essencial dos direitos

${ }^{19}$ Cf. tópico IV. 
fundamentais e a eficácia das normas constitucionais" (2006)- a qual relativiza ambos os conceitos, deixando claro que, por um lado, acreditar em uma eficácia plena poderia implicar na falsa conclusão de que nada deve ser feito para garantir a eficácia dessas normas (por se crer que são, em sua natureza, plenas), enquanto, por outro lado, acreditar que certas normas detêm eficácia tão somente limitada poderia ocasionar o pensamento de que, no âmbito da separação dos poderes, nenhuma ação incumbiria àqueles que operam o Direito, a não ser aguardar pela regularização autorizadora de ações com o fim de trazer eficácia a esses direitos. Sobre isso, afirma o autor:

Se tudo é restringível, perde sentido qualquer distinção que dependa da aceitação ou rejeição de restrições a direitos - logo, não se pode distinguir entre normas de eficácia plena e normas de eficácia contida ou restringível; além disso, se tudo é regulamentável e, mais do que isso, depende de regulamentação para produzir todos os seus efeitos, perde sentido qualquer distinção que dependa da aceitação ou rejeição de regulamentações a direitos - logo, não se pode distinguir entre normas de eficácia plena e normas de eficácia limitada. (SILVA, 2006, p.46)

Nesse contexto, deve-se ressaltar que todo direito tem um custo social para que seja implementado, sejam eles sociais ou individuais. Estes, "embora elevadíssimos, não são percebidos porque estão embutidos no custo do aparato estatal (agências reguladoras de proteção aos mercados, serviços de polícia e Poder Judiciário para proteção da propriedade e dos contratos etc.)" (MASTRODI, 2014, p. 583). É justamente isto o que causa a falsa impressão de que somente aqueles, os sociais, geram vultosos dispêndios.

Por essa lógica disfarçada, além de se tornarem ainda mais escassos os recursos públicos restantes para sua aplicação na efetividade dos direitos sociais, fica também em segundo plano a atenção voltada para esses direitos, pois, em relação à usual concepção de direito subjetivo, a estrutura da Teoria Geral do Direito somente se refere a um direito subjetivo em relação aos direitos individuais, como o direito à propriedade, mas não em relação aos sociais, como direito à moradia, motivo pelo qual, nessa estrutura, estes direitos ficam subordinados àqueles.

Assim, ao se refletir sobre a eficácia do direito à moradia, deve-se apontar, que a positivação desse direito como fundamental- seja com a incorporação formal por meio da EC no 20/2006, seja com a incorporação material em nossa ordem interna, por meio dos tratados e pactos internacionais precedentes- parece relevante para o trato dessa questão sob uma abordagem somente abstrata, mas não realista. 
Importa, aqui, refletir sobre a real eficácia do direito à moradia no âmbito da realidade social e, nesta, vale menos a forma pela qual este direito é expresso no ordenamento jurídico do que o conteúdo que o permeia, diante dos interesses que predominam na sociedade.

Nota-se, então, que há hoje, assim como antes, o tratamento do direito à moradia apenas como posse de um bem imóvel com a finalidade de residência, subordinado ao direito de propriedade, já que, segundo a teoria geral do direito, a posse é um componente do direito de propriedade e não um direito autônomo.

\section{CONSIDERAÇÕES FINAIS}

Constatamos que, mais do que a simples relativização do conceito de propriedade, é possível defender, no âmbito da propriedade urbana, a subordinação da propriedade do imóvel residencial urbano à moradia - direito social fundamental que, concretamente, identifica o uso efetivo do imóvel segundo sua função social.

Não obstante, vimos que interesses políticos e socioeconômicos de ordem liberal explicam o porquê de a estrutura jurídica estar posta de modo a garantir abstratamente a propriedade, independentemente da concreção de seu uso, apesar da previsão legal de limitações a esse direito. Tais interesses são baseados em direitos individuais absolutos e de não intervenção estatal e estão em conformidade com a estrutura original da Teoria Geral do Direito, de base liberalista, que, ao estruturar o direito na forma de garantias absolutas entre sujeitos de direito de igual dignidade perante a lei, permanece estática às carências da realidade social.

Perpetua-se, então, o tratamento da posse como componente do direito de propriedade e não como direito autônomo, sob a lógica das relações privadas, de crédito e débito. Em contraposição a essa estrutura liberal enraizada em nosso meio social e, consequentemente, jurídico, defendemos a necessidade de rompimento da manutenção das teorias possessórias do direito privado e a compreensão de que a moradia (aplicação finalística e concreta do uso de uma propriedade urbana) é uma necessidade real e concreta a ser satisfeita, um interesse social legítimo e que, portanto, há de ser compreendida como superior ao direito à propriedade.

\section{REFERÊNCIAS BIBLIOGRÁFICAS}

BOBBIO, Norberto. A Era dos Direitos. Trad. Carlos Nelson Coutinho. Apresentação de Celso Lafer. Nova Ed. Rio de Janeiro: Elsevier, 2004. 
BONALDO, Frederico. O Direito Subjetivo de Propriedade em Face da Coexistência Humana. Revista de Direito da Cidade, v. 5, n. 1, 2013, p.117-145. Disponível em: http://dx.doi.org/10.12957/rdc.2013.9726. Acesso em: 17 de agosto de 2015.

COMPARATO, Fábio Konder. Direitos e Deveres fundamentais em matéria de propriedade. Revista CEJ, v.1 n.3, set. /dez. 1997, p. 1-12. Disponível em: http://www.jf.jus.br/ojs2/index.php/revcej/article/view/123/166. Acesso em 17 de agosto de 2015.

GIL, António Hernadez. Función social de la posesión. Alianza Editorial: Madrid, 1969.

HEIS, Bruno Dalpian. O Direito à Moradia e a Necessidade de sua Efetivação por Parte do Estado. Porto Alegre, 2013. Trabalho de Conclusão de Curso (Bacharelado em Direito). Universidade Federal do Rio Grande do Sul, Porto Alegre.

IHERING, Rudolf Von. O fundamento dos interditos possessórios. Trad. Aderbal de Carvalho. 2. ed. Rio de Janeiro, Francisco Alves, 1908.

KELSEN, Hans. Teoria pura do direito. Trad. João Baptista Machado. 7. ed. São Paulo: Martins Fontes, 2000.

MASTRODI, Josué. Ponderação de Direitos e Proporcionalidade das Decisões Judiciais. Revista Direito GV [online], v.10, n.2, 2014, p. 577-595. Disponível em: http://dx.doi.org/10.1590/18082432201424. Acesso em 15 de agosto de 2015.

Sobre o real fundamento dos Direitos Fundamentais. Revista Digital de Direito Público, vol. 1, n. 1, 2012, p. 150 - 187. Disponível em: http://revistas.usp.br/rddp/article/view/7665. Acesso em 10 de fevereiro de 2014.

MASTRODI, Josué; SILVA, Márcia Maria Carvalho da. O direito fundamental social à moradia e a teoria geral do direito. Revista Direitos Fundamentais \& Justiça, n. 21, 2012, p. 145-162. Disponível em http://www.dfj.inf.br/Arquivos/PDF_Livre/21_Doutrina\%20Nacional\%206_OK.pdf. Acesso em 15 de agosto de 2015.

MORAES, Maria Celina Bodin de. A caminho de um Direito Civil Constitucional. Revista Estado, Direito e Sociedade, v. I, 1991, p. 1-22. Disponível em: http://www.egov.ufsc.br/portal/sites/default/files/anexos/15528-15529-1-PB.pdf. Acesso em 10 de setembro de 2014.

OLIVEIRA, Álvaro Borges de; MACIEL, Marcos Leandro. Estado da arte das teorias possessórias. Revista Direitos Fundamentais \& Democracia (UniBrasil), v.5, p. 1-14, 2009. Disponível em http://revistaeletronicardfd.unibrasil.com.br/index.php/rdfd/article/view/90/89. Acesso em 15 de agosto de 2015.

PAGANI, Elaine Adelina. $\mathrm{O}$ direito de propriedade e o direito à moradia: um diálogo comparativo entre o direito de propriedade urbana imóvel e o direito à moradia. Porto Alegre: EDIPUCRS, 2009.

PEIXOTO, Ester Lopes. A função social da propriedade: do CC/1916 ao CC/2002. Dissertação de Mestrado. Universidade Federal do Rio Grande do Sul. Porto Alegre. 2005. Disponível em: 
http://www.lume.ufrgs.br/bitstream/handle/10183/7496/000546278.pdf?...1. Acesso em: 12/12/2014.

PENTEADO, Luciano de Camargo. Direito das Coisas. 2. Ed. rev., atual. e ampl. São Paulo: Revista dos Tribunais, 2012.

RENNER, Karl. The institutions of private law and their social functions. Trad. Agnes Schwarzschild. Londres: Routledge \& Kegan, 1949.

ROLNIK, Raquel. Moradia é mais que um objeto. Revista eletrônica e-metropolis, no $05 \cdot$ ano 2, junho de 2011, p.37. Disponível em: www.emetropolis.net. Acesso em 23 de março de 2015. Entrevista concedida à Revista eletrônica e-metropolis.

SARLET, Ingo Wolfgang. O Direito Fundamental à Moradia na Constituição: Algumas Anotações a Respeito de seu Contexto, Conteúdo e Possível Eficácia. Revista Direito e Democracia, Canoas. Vol. 4, n.2, 2.Sem.2003, p.327-383.

SILVA, Virgílio Afonso da. O conteúdo essencial dos direitos fundamentais e a eficácia das normas constitucionais. Revista de Direito do Estado 4, 2006, p. 23-51.

TROPER, Michel. A filosofia do direito. Trad. Deiró. São Paulo: Martins Fontes, 2008.

Trabalho enviado em 18 de agosto de 2015.

Aceito em 08 de outubro de 2015. 